Original Research Paper

\title{
Developing an Anthropometric Database for Saudi Students and Comparing Saudi Dimensions relative to Turkish and Iranian Peoples
}

\author{
${ }^{1,2}$ Mohamed A.A. Mansour \\ ${ }^{1}$ Department of Industrial Engineering, College of Engineering, \\ Zagazig University, Zagazig, Al-Sharkia 44519, Egypt \\ ${ }^{2}$ Department of Industrial Engineering, College of Engineering, \\ King Khalid University, Abha, Asser, 394, Kingdom of Saudi Arabia
}

Article history

Received: 13-06-2016

Revised: 16-06-2016

Accepted: 24-06-2016

Email: momansor@kku.edu.sa

\begin{abstract}
The main objectives are to develop an anthropometric database for Saudi Students and to compare it relative to two other Middle Eastern people. A national anthropometric standard for Saudis does not exist and few studies have focused on the development of Saudis anthropometric data and the comparison of them with other races. The availability of these data is necessary to design new products and to reduce the discomfort/pain from using the man-machine systems. A random sample of 900 male students aged 19-30 years at King Khalid University in Saudi Arabia participated in the study. Twelve body dimensions were measured and described in terms of mean, standard deviations, 5/95th percentiles and the significance value for Kolmogorov-Smirnov test by using the Minitab software. The 2-sample $t$ test was performed at 0.05 to compare the means of two Saudi anthropometric studies (including this one) relative to other published studies for two Turkish and two Iranian studies. Hutson (1999) procedure was used to estimate the confidence interval for 5/95th percentiles and to compare them among Saudi, Turks and Iranians. The 12 dimensions were found to be normally distributed with significance values $\geq 0.054$. The Saudi body weight, bideltoid breadth, buttock-popliteal length and sitting popliteal height were found to be larger than those of the Turkish and Iranian students, while in every other dimension, the Saudis were smaller. There is a statistically significant difference between the mean and 5/95th percentile weight (71.61, $46.65,93.69) \mathrm{kg}$ among Saudi, Turks and Iranians. The 5/95th percentiles $(31.39,39.39) \mathrm{cm}$ for sitting hip breadth, the 5 th percentile $(55.08 \mathrm{~cm})$ of buttock-knee length and the 95 th percentile $(46.98 \mathrm{~cm})$ of sitting popliteal height are significantly equal for the Saudis and Turks. The sitting eye height 5th percentile of $72.12 \mathrm{~cm}$ and the sitting popliteal height 95th percentile of $46.98 \mathrm{~cm}$ are significantly equal Saudis and Iranians. This study updates the anthropometric data for Saudi people that is rare in literature. The mean for the 12 anthropometric dimensions are significantly different among Saudis, Turks and Iranians. Also, most of 5th and 95th percentiles for Saudis dimensions are different from Turks and Iranians. There is a very noticeable difference between the body types of Saudis and those of Turks and Iranians. Therefore, the anthropometric information of one country cannot necessarily be implemented in other regions. The study data provides a great value for designing university facilities. The comparison results can be used to give priority for importing tools/equipments to countries of dimensions near to Saudi students.
\end{abstract}

Keywords: Anthropometric Survey, Anthropometric Differences, University Students, Saudi Arabia, Turkey, Iran, Statistical Analysis 


\section{Introduction}

The anthropometric dimensions vary between different age groups according to (Martin and Soldo, 1997) and between different professional groups according to (Mebarki and Davies, 1990) and between different countries (Fernandez et al., 1989). Therefore, an anthropometric database/standard is necessary for each country for all age groups and professions in order to use it as an input parameter in the design of comfortable products/tools (Agrawal et al., 2010). No anthropometric data/standard does exist for Saudi people available in Saudi standards, Metrology and Quality Organization. Also, there is a limited number of published research concerned with collecting anthropometric data for Saudi people and comparing it with other people (Taha et al., 2009).

Pain, posture-related syndromes and become accustomed to sit/work in wrong posture may result from using uncomfortable university/school facilities as desks and chairs by students (Aagaard-Hansen and Storr-Paulsen, 1995; Murphy et al., 2004; Milanese and Grimmer, 2004; Cardon et al., 2004). In order to solve this problem, we need to design facilities according to the anthropometric dimensions of students to achieve comfort, safe and healthy use interaction between students and the used facilities. For example, Tunay and Melemez (2008) considered Popliteal height and seat height mismatch, Gouvali and Boudolos (2006) considered Hip breadth and seat width mismatch, Mohamed Thariq et al. (2010) considered Buttock-popliteal length and seat depth mismatch, Milanese and Grimmer (2004) considered Elbow height and desktop height mismatch and Openshaw and Taylor (2006) considered hip breadth and the distance between the armrests.

The present paper presents an anthropometric study for Saudi students at College of Engineering at King Khalid University to collect and describe twelve anthropometric dimensions for Saudi people in statistical measures. Also, the paper present a comparative study between the collected data for Saudi with other published data for Saudi, Turkish and Iranian people. On the basis of these two objectives, the appropriate measuring instruments were used to collect the data and Minitab software was used as a statistical package to describe and analyze these data. The 2 sample $t$ test for independent samples from unknown variance populations and Hutson (1999) procedure for quantile inference were used as analysis techniques.

The developed database in the current study is considered an update for the little data available in the anthropometry literature for Saudi people and is considered as a basic study comparing the body dimensions among three Middle Eastern people (Saudis, Turkish and Iranians). The results of this paper provided sufficient justification on the importance of conducting anthropometric surveys for Saudi Arabia with large sample and to compare the anthropometry of different countries in the Middle Eastern region and the world.

\section{Literature Review}

There is a need to collect and describe the anthropometric dimensions of university and school students to enable the appropriate design of education facilities and equipment. Ergonomic and anthropometric data are used to design comfortable and safe products/equipment and processes (Wichansky, 2000; Pentikis et al., 2002). Musculoskeletal disorders, premature fatigue and several other issues can result from the use of inappropriate equipment (Prado-Lu, 2004). The establishment of anthropometric databases for different population groups has thus gained tremendous popularity over the past few years (Bolstad et al., 2001; Wang et al., 2002). Ethnic diversity in terms of bodily proportions should be considered in addition to the mean dimensions (Lin et al., 2004).

\section{Turkish Data Used in this Study}

Tunay and Melemez (2008) stated "In this study, the necessary anthropometric measurements of classroom furniture used in Turkey's higher education were carried out. The static anthropometric measurements of 13 dimensions from 1049 students were obtained while they were standing and sitting. The data obtained was analyzed to determine the limit values to be used in the classroom and laboratory design. The dimensions of school desks and chairs were compared with the students' anthropometric measurements. For male students, the average weight was $69.50 \mathrm{~kg}$, their height was $1749 \mathrm{~mm}$ and their popliteal height was $433 \mathrm{~mm}$. For female students, the average weight was found to be $56.02 \mathrm{~kg}$, their height was $1618 \mathrm{~mm}$ and their popliteal height was $421 \mathrm{~mm}$. From these anthropometric measurements, a mismatch was observed between the popliteal height and the seat height, the knee height and the desk clearance and the buttock to popliteal length and the seat depth. Percentile values for the ergonomic design of school desks and chairs are presented. The results show that there are significant differences between the anthropometric values for Turkish students and other those of other nationalities."

Turgut et al. (2004) conducted an anthropometric study of Turkish males and females, producing data that was used to design the desks and chairs used at Cukurova universities in Turkey.

\section{Iranian Data Used in this Study}

An anthropometric database for the students of Tehran University was developed by Mououdi (1997). 
Approximately 28 anthropometric dimensions were measured and described in statistical terms for 105 males and 74 females, aged between 20 and 30 years. Mirmohammadi et al. (2011) conducted a cross-sectional anthropometric study of Iranian university students and used the obtained data for the design of furniture. Approximately 20 dimensions were measured for 911 Iranian students (475 males and 436 females). The data were compared with the findings of the research conducted by Mououdi (1997) and three other populations. The comparison indicated that there is a significant difference between populations, in terms of anthropometric characteristics (Mortazavi et al., 2008; Sadeghi et al., 2014).

Sadeghi et al. (2010) compared the static anthropometric characteristics of three Iranian ethnic groups, including Fars, Azeris and Arabs, by applying an "Analysis of Variance" (ANOVA) and post-hoc tests. The results indicated that there were notable differences between the three ethnic groups, for both males and females $(\mathrm{P}$-value $<0.05)$. On the other hand, Sadeghi et al. (2010) also investigated the compatibility of educational furniture along with the anthropometric dimensions of students studying at the Isfahan University of Medical Sciences. Habibi et al. (2012) also contrasted British and American standards with the anthropometric information for Iranian students, for 30 dimensions. The acquired results showed considerable differences between non-Iranians and Iranians. A survey of the literature revealed that limited anthropometry studies have been conducted; hence, profound and coherent studies must be performed.

Shaheen et al. (2011) performed an anthropometric study in which they collected and analyzed 13 dimensions, related to the classroom furniture used in Turkey's higher education system. It was observed that there is a significant difference between the dimensions of Turkish students and those of other nationalities, as noted by Pheasant and Haslegrave (2005). Also, it was observed that there is a mismatch between the Turkish university students' dimensions and the desk/chair dimensions. Gouvali and Boudolos (2006) established that there is an overwhelming requirement for adjustability in school furniture, while considering the anthropometric dimensions in different regions, ages and genders.

\section{Saudi Anthropometric Database}

Taha et al. (2009) stated "This study presents a comparison of the anthropometric characteristics of 241 Malaysian and 646 Saudi Arabian males aged 20 to 30 years. The mean values, Standard Deviation (SD) and 5th and 95th percentile values of the 26 measurements and 22 proportions of each group were obtained. The results showed that there are significant differences in a number of the body dimensions of these populations, except for eye height and elbow height (standing), as well as height, eye height, shoulder height and elbow height (sitting). These values are important to the ergonomic design of workstations, personal protective equipment, tools, interface systems and furniture: The presented data may be useful for providing a safer, more productive and user-friendly workplace for Malaysian and Saudi Arabian populations."

Ethnic diversity is always a significant factor that may relate to differences in the body dimensions and the scopes of their applications. Turkey, Iran and Saudi Arabia are all located in the Middle East. However, these three countries are quite different from a genetic point of view. Saudis consist of two ethnic groups, namely, 90\% Arab and 10\% AfroAsian. Turks consist of two ethnic groups, that is, $80 \%$ Turks and $20 \%$ Kurdish, while Iranians consist of no less than nine groups, specifically, 51\% Persian, 24\% Azerbaijani 8\% Gilaki and Mazandarani, 7\% Kurd, 3\% Arab, 2\% Lur, 2\% Baloch, 2\% Turkmen and $1 \%$ other. The natural environments of these countries are also different, such that it is very possible that they have different anthropometric characteristics due to genetic differences.

According to the highlighted review above, no studies have been conducted to build an anthropometric database for Saudi students. It would, therefore, be interesting to find out whether there are significant differences in their body dimensions relative to other peoples living in the Middle East. Consequently, there is a need for a new Saudi anthropometric study which would set a landmark for further anthropometric predictions and provide designers with an updated source for the user-centered design of products and workplaces.

The overall objective of this research was to collect and describe 12 anthropometric measures for the Saudi students of the College of Engineering, King Khalid University, KSA and to then compare them with the body dimensions of Turks and Iranians.

\section{Materials and Methods}

\section{Participants}

Nine hundred students from five Engineering departments of the College of Engineering of King Khalid University were selected as a sample. None of the students had a history of trauma or congenital anomalies. Ethical approval was obtained from the appropriate authority within the institute. To acquire pertinent results, twenty students were chosen at random for each level at the College. Measurements 
were taken from January 2014 until June 2014, i.e., over a period of five months. The age of the subjects ranged from 19 to 30 years at the time of the survey with a standard deviation of 1.79 years and an average of 23.89 years. All of the subjects were lightly clothed and barefooted for the measurements. The measurements were carried out in the human factors laboratory which equipped with the necessary measuring instruments.

\section{Methodology of Measurement}

In this cross-sectional study, twelve different anthropometric dimensions of the Saudi students were measured. Each student selected for the measurements wore shorts but no shoes. During the research, 12 twelve static anthropometric dimensions were measured, namely, weight, height, bideltoid breadth, hip breadth (sitting), popliteal height (sitting), knee height, buttock-popliteal length, buttock-knee length, waist height (sitting), acromial height (sitting), eye height (sitting) and sitting height (Chung and Wong, 2007; Jung, 2005; Musaiger and Al-Hazzaa, 2012). One of the main reasons for the selection of these dimensions is that they are commonly applied to the design of furniture. A random sampling technique was used to generate random university identity numbers corresponding to student engaged in the study.

The measuring instruments used in this survey included an anthropometer, buttock plate, weight scale and beam caliper. The measurements were carried out by trained industrial engineering students undergoing a comprehensive training course which focused on land-marking. Therefore, they had been using the relative measuring instruments for four months (Mououdi, 1997). Ten percent of the measurements were re-checked by a reviewing member (Khalaf et al., 2013). Table 1 lists the United States reference numbers (US Ref. No.) for the dimensions addressed by the research, the name and description of the twelve anthropometric dimensions.

\section{Data Analysis}

To acquire the required results, the collected data were analyzed by using the Minitab ${ }^{\circledR}$ 16.1.1 software. In addition to this, descriptive and analytical statistics were applied to describe the collected data in terms of central tendency measures and percentile values. The Kolmogorov-Smirnov test was used to assure the normality of the collected data. In addition, the 2 sample $t$ test was utilized to determine whether there were any statistically significant differences between the three ethnicities addressed by the current research. The analysis was based on the assumption that the samples were drawn from normal populations with unknown standard deviations (Dianat et al., 2013). Moreover, Hutson (1999) procedure was used to calculate nonparametric confidence intervals for quantiles using fractional order statistics since percentile values were used in real man-machine design problems.

Table 1. US Ref. No., name and description of twelve anthropometric dimensions

\begin{tabular}{|c|c|c|}
\hline US ref. no. & Ref. no. name & Description \\
\hline 125 & Weight & Weight. \\
\hline 100 & Stature & Perpendicular distance from standing surface to top of the head. \\
\hline 13 & Bideltoid breadth & $\begin{array}{l}\text { Maximum parallel distance between the tangential margins of the upper arms on } \\
\text { the deltoid muscles. }\end{array}$ \\
\hline 67 & Hip breadth, sitting & $\begin{array}{l}\text { Tangential tight breadth or hip breadth (whichever is broader) of the subject, seated } \\
\text { on the surface. }\end{array}$ \\
\hline 94 & Sitting height & Perpendicular distance between the top of the head and sitting surface. \\
\hline 50 & Eye height, sitting & $\begin{array}{l}\text { Perpendicular distance between the ectocanthus landmark at eye's outer corner and } \\
\text { the sitting surface. }\end{array}$ \\
\hline 4 & Acromial height, sitting & $\begin{array}{l}\text { Perpendicular distance between the acromion landmark on the shoulder tips and sitting } \\
\text { surface. }\end{array}$ \\
\hline 122 & Waist height sitting & $\begin{array}{l}\text { Perpendicular distance between the center of the omphalion (navel) and the sitting } \\
\text { surface. }\end{array}$ \\
\hline 27 & Buttock-knee length & $\begin{array}{l}\text { Parallel distance between the most subsequent point on either buttock or the front of the } \\
\text { knee, as calculated in the sitting position along with the knees, when bent at } 90^{\circ} \text {. }\end{array}$ \\
\hline 28 & Buttock-popliteal length & $\begin{array}{l}\text { Parallel distance between the subsequent point on the buttock and back of the knee when } \\
\text { the subject is sitting with their knees bent at } 90^{\circ} \text {. }\end{array}$ \\
\hline 73 & Knee height & $\begin{array}{l}\text { Perpendicular distance between the standing surface and the center of the knee at the } \\
\text { midpatella landmark. }\end{array}$ \\
\hline 87 & Popliteal height, sitting & $\begin{array}{l}\text { Perpendicular distance between the bottom of the thigh and the bottom of the foot, } \\
\text { measured at the back of the knee. The seating position of the subject is with the knees } \\
\text { bent at } 90^{\circ} \text { and the thighs parallel with the floor. }\end{array}$ \\
\hline
\end{tabular}




\section{Results}

\section{The Anthropometric Data for Saudi Students}

Table 2 presents the basic descriptive statistics for the 12 anthropometric dimensions for Saudis in terms of the mean, Standard Deviation (SD), 5th/95th percentiles and the significance value for Kolmogorov-Smirnov test (KS Sig.) for every dimension (Motamedzade et al., 2009; Sadeghi et al., 2010). In the table, we note that there is no reason to reject that the 12 dimensions follow the normal distribution with 0.05 level of significance. Also, the minimum $\alpha$ equals to 0.054 for KS test and $50 \%$ of data have KS Sig. $\geq 0.111$ indicating that higher level of normality.

The data given in Table 2 can be considered as an update for Saudi anthropometric data provided by Taha et al. (2009). The data can be used as input parameters for designing university facilities as classroom furniture, laboratory desks and chairs and library tables.

\section{Comparison of Mean Anthropometric Dimensions for Same Populations}

Two Saudi studies, two Turkish studies and two Iranian studies were compared in terms of their difference (Ed) of the mean anthropometric dimension, 95\% CI for difference, T-value and P- value, as determined with the Minitab ${ }^{\circledR}$ 16.1.1 software. The comparisons were done using the 2 independent sample $t$ test drawn from two populations with unknown variances with significance level of 0.05 Karmegam et al. (2011).

\section{Comparison with Saudi Arabian Anthropometric Database}

In this section, we compare the work done by Taha et al. (2009) with the results of the current study. Table 3 depicts the 2 sample $t$ test results of comparing the Saudi anthropometric literature. The Pvalues of 0.988 and 0.593 correspond to the statistical significance of the weight and height, respectively, indicating that there is no evidence that would support the rejection of the difference between the results obtained by Taha et al. (2009) and those of the current study regarding weight and height. There is a significant difference between the buttock-popliteal length and popliteal height (sitting), as obtained by the two studies, in that Taha et al. (2009) obtain values for the two dimensions that are higher than those obtained by the current study. The current study produced lower values for the sitting hip breadth, sitting height, sitting eye height, sitting acromial height and buttock-knee length.

Table 2. Statistics for sample of 900 Saudi Arabian students

\begin{tabular}{llrrrrr}
\hline US ref. no. & Ref. no. name & Mean & \multicolumn{1}{c}{ SD } & \multicolumn{1}{c}{5 th } & 95 th & KS Sig. \\
\hline 125 & Weight & 71.61 & 12.60 & 46.65 & 93.69 & 0.118 \\
100 & Stature & 170.10 & 4.95 & 161.62 & 177.79 & 0.152 \\
13 & Bideltoid breadth & 47.95 & 3.53 & 41.53 & 53.87 & 0.092 \\
67 & Hip breadth, sitting & 35.40 & 2.33 & 31.39 & 39.17 & 0.077 \\
94 & Sitting height & 89.20 & 3.55 & 82.73 & 94.11 & 0.054 \\
50 & Eye height, sitting & 77.12 & 3.29 & 72.12 & 81.57 & 0.111 \\
4 & Acromial height, sitting & 58.15 & 2.87 & 53.98 & 63.38 & 0.094 \\
122 & Waist height sitting & 22.93 & 1.49 & 19.74 & 26.01 & 0.096 \\
27 & Buttock-knee length & 59.51 & 2.78 & 55.08 & 64.03 & 0.200 \\
28 & Buttock-popliteal length & 48.24 & 2.77 & 43.64 & 52.54 & 0.200 \\
73 & Knee height & 48.55 & 2.49 & 45.38 & 53.04 & 0.112 \\
87 & Popliteal height, sitting & 41.73 & 2.89 & 35.48 & 46.98 & 0.152 \\
\hline
\end{tabular}

Table 3. Results of 2 sample $t$ test and confidence interval for Saudi data

\begin{tabular}{|c|c|c|c|c|}
\hline \multirow{2}{*}{$\begin{array}{l}\text { Articles } \\
\text { US ref. no. }\end{array}$} & \multicolumn{4}{|c|}{ Taha et al. (2009) Vs. Current study } \\
\hline & $\mathrm{Ed}$ & $95 \% \mathrm{CI}$ & T-Value & P-Value \\
\hline 125 & -0.01 & $(-1.285 ; 1.265)$ & -0.02 & 0.98 \\
\hline 100 & -0.18 & $(-0.840 ; 0.480)$ & -0.54 & 0.59 \\
\hline 67 & -0.39 & $(-0.734 ;-0.046)$ & -2.23 & 0.02 \\
\hline 94 & -4.30 & $(-4.772 ;-3.828)$ & -17.88 & 0.00 \\
\hline 50 & -3.01 & $(-3.466 ;-2.554)$ & -12.95 & 0.00 \\
\hline 4 & -1.09 & $(-1.533 ;-0.647)$ & -4.83 & 0.00 \\
\hline 27 & -2.27 & $(-2.597 ;-1.943)$ & -13.62 & 0.00 \\
\hline 28 & 0.76 & $(0.420 ; 1.100)$ & 4.39 & 0.00 \\
\hline 87 & 4.84 & $(4.526 ; 5.154)$ & 30.23 & 0.00 \\
\hline
\end{tabular}




\section{Comparison with Turkish Anthropometric Database}

We compared our results with the anthropometric data for Turkish students, available in the literature as the work of Tunay and Melemez (2008) and Turgut et al. (2004), as shown in Table 4. An analysis revealed that the collected dimensions differ from each other, as shown in the Pvalue column. There is a statistically significant variation for all of the dimensions, especially for the sitting popliteal height for which the value of Ed is 8.95.

\section{Comparison with Iranian Anthropometric Database}

The collected Iranian anthropometric dimensions are presented in two research papers, although there is a difference in the values of the dimensions depending on the study. These studies were undertaken by Mirmohammadi et al. (2011) and Habibi et al. (2012). There is no statistical difference in the value for the height as given in Mirmohammadi et al. (2011) and Habibi et al. (2012), or knee height in Mirmohammadi et al. (2011) and Habibi et al. (2012). The clear and significant variability among Iranians is due the fact that there are nine ethnic groups within the country Sadeghi et al. (2014). Table 5 depicts the results of the 2 sample $t$ test and the confidence interval for Iranian anthropometric data available in the literature.

\section{Comparison of Mean Anthropometric Dimensions of Turkish and Iranian Populations}

Table 6 compares the anthropometric dimensions of Turks and Iranians in terms of the Ed and P-values. The results indicate a large variability between the anthropometric data for Turks and Iranians due to there being nine different ethnic groups within Iran, while Turkey has two main ethnic groups.

\section{Comparison of Mean Anthropometric Dimensions for Saudi, Turkish and Iranian Populations}

The anthropometric dimensions of Saudi, Turk and Iranian students were compared in terms of their (Ed, Pvalue) as listed in Table 7 . The results of the current study and that of Taha et al. (2009) were used as the available anthropometric dimensions for Saudis, for comparison with the data for Turkish and Iranian people.

The Saudi body weight, bideltoid breadth, buttockpopliteal length and sitting popliteal height were found to be larger than those for the Turkish and Iranian students, while the remaining dimensions were smaller in the Saudis, relative to the Turks and Iranians. The variation in the body dimensions of the Saudis and Iranians was found to be greater than that between the Saudis and Turks.

\section{The 95\% Confidence Intervals for Saudi Data and Hypothesis Tests for Percentile Values}

The $95 \%$ confidence intervals for 5 th/95th percentile values of the 12 Saudi anthropometric dimensions were estimated based on Hutson (1999) procedure as shown in Table 8. The lower and upper levels are shown in columns 4 and 5 . Three hypothesis test for each published study were calculated $\left(\mathrm{H}_{0}: \mathrm{b}=\mathrm{H}_{0}\right)$ in decisions columns, $\mathrm{H}_{1}: \mathrm{b}<\mathrm{H}_{0}$ and $\mathrm{H}_{1}: \mathrm{b}>\mathrm{H}_{0}$ at significance level of 0.05 . Decision columns includes only logical digit $(0$ or 1). The " 0 " value indicates that do not reject $\mathrm{H}_{0}$ while the " 1 " digit indicates that reject $\mathrm{H}_{0}$. In this section, the objective is to test whether there is a significance difference between population 5th/95th percentiles for Saudi, Turkish and Iranians anthropometric dimensions.

Table 4. 2 sample $t$ test and confidence interval for Turks data

\begin{tabular}{|c|c|c|c|c|}
\hline \multirow{2}{*}{$\begin{array}{l}\text { Articles } \\
\text { US ref. no. }\end{array}$} & \multicolumn{4}{|c|}{ Tunay and Melemez (2008) Vs. Turgut et al. (2004) } \\
\hline & Ed & $95 \% \mathrm{CI}$ & T-value & P-value \\
\hline 13 & -2.80 & $(-3.029 ;-2.571)$ & -23.97 & 0.00 \\
\hline 67 & -2.90 & $(-3.143 ;-2.657)$ & -23.46 & 0.00 \\
\hline 28 & 2.90 & $(2.631 ; 3.169)$ & 21.16 & 0.00 \\
\hline 73 & 1.40 & $(1.158 ; 1.642)$ & 11.35 & 0.00 \\
\hline 87 & 8.95 & $(8.685 ; 9.215)$ & 66.28 & 0.00 \\
\hline
\end{tabular}

Table 5. 2 sample t test and confidence interval for Iranian anthropometric data

\begin{tabular}{|c|c|c|c|c|}
\hline \multirow{2}{*}{$\begin{array}{l}\text { Articles } \\
\text { US ref. no. }\end{array}$} & \multicolumn{4}{|c|}{ Mirmohammadi et al. (2011) Vs. Habibi et al. (2012) } \\
\hline & Ed & $95 \%$ CI & T-Value & P-Value \\
\hline 125 & -10.900 & $(-11.877 ;-9.923)$ & -21.90 & 0.000 \\
\hline 100 & -0.710 & $(-1.636 ; 0.216)$ & -1.50 & 0.133 \\
\hline 13 & -2.870 & $(-4.124 ;-1.616)$ & -4.50 & 0.000 \\
\hline 94 & -- & - & -- & -- \\
\hline 50 & -- & -- & -- & -- \\
\hline 27 & 8.230 & $(7.774 ; 8.686)$ & 35.43 & 0.000 \\
\hline 28 & -- & -- & -- & -- \\
\hline 73 & -0.050 & $(-0.451 ; 0.351)$ & -0.24 & 0.807 \\
\hline 87 & -0.370 & $(-0.705 ;-0.035)$ & -2.17 & 0.030 \\
\hline
\end{tabular}


Table 6. Comparison of Turkish and Iranian anthropometric dimensions (Ed,P-value)

\begin{tabular}{llll}
\hline & & Iran & \\
Article & US ref. no. & - Mirmohammadi et al. (2011) & Habibi et al. $(2012)$ \\
\hline Tunay and Melemez (2008) & 125 & $(11.4,0.00)$ & $(0.50,0.15)$ \\
& 100 & $(0.71 .0 .03)$ & $(-1.90,1.00)$ \\
& 13 & $(0.97,0.00)$ & -- \\
& 67 & - & -- \\
& 94 & $(1.49,0.00)$ & -- \\
Turgut $e t$ al. $(2004)$ & 50 & $(3.5,0.00)$ & -- \\
& 122 & $(-1.45,0.00)$ & $(10.70,0.00)$ \\
& 27 & $(2.47,0.00)$ & -- \\
& 28 & $(1.77,0.00)$ & $(0.90,0.00)$ \\
& 73 & $(0.95,0.00)$ & $(0.70,0.00)$ \\
& $(1.07,0.00)$ & -- \\
\end{tabular}

Table 7. Comparison between Saudi, Turkish and Iranian anthropometric dimensions (Ed,P-value)

\begin{tabular}{|c|c|c|c|c|c|}
\hline \multirow[b]{2}{*}{ Article } & \multirow[b]{2}{*}{ US Ref. No. } & \multicolumn{2}{|l|}{ Turkey } & \multicolumn{2}{|l|}{ Iran } \\
\hline & & $\begin{array}{l}\text { Tunay and } \\
\text { Melemez (2008) }\end{array}$ & $\begin{array}{l}\text { Turgut et al. } \\
(2004)\end{array}$ & $\begin{array}{l}\text { Mirmohammadi et al. } \\
(2011)\end{array}$ & $\begin{array}{l}\text { Habibi et al } \\
(2012)\end{array}$ \\
\hline \multirow[t]{12}{*}{ Current study $(\mathrm{n}=900)$} & 125 & $(2.11,0.00)$ & -- & $(13.51,0.00)$ & $(2.61,0.00)$ \\
\hline & 100 & $(-4.80,0.00)$ & -- & $(-4.09,0.00)$ & $(-4.80,0.00)$ \\
\hline & 13 & $(4.85,0.00)$ & $(2.05,0.00)$ & $(5.82,0.00)$ & $(2.95,0.00)$ \\
\hline & 67 & $(0.300,0.00)$ & $(-2.60,0.00)$ & -- & -- \\
\hline & 94 & $(-2.00,0.00)$ & -- & $(-0.51,0.01)$ & -- \\
\hline & 50 & $(-4.28,0.00)$ & -- & $(-0.78,0.00)$ & -- \\
\hline & 4 & $(-3.05,0.00)$ & -- & -- & -- \\
\hline & 122 & $(-0.77,0.00)$ & -- & $(-2.22,0.00)$ & -- \\
\hline & 27 & $(-1.39,0.00)$ & -- & $(1.08,0.00)$ & $(9.31,0.00)$ \\
\hline & 28 & $(-0.56,0.00)$ & $(2.34,0.00)$ & $(1.21,0.00)$ & -- \\
\hline & 73 & $(-6.15,0.00)$ & $(-4.75,0.00)$ & $(-5.20,0.00)$ & $(-5.25,0.00)$ \\
\hline & 87 & $(-1.57,0.00)$ & $(7.38,0.00)$ & $(-0.50,0.00)$ & $(-0.87,0.00)$ \\
\hline \multirow[t]{9}{*}{ Taha et al. (2009) } & 125 & $(2.10,0.00)$ & -- & $(13.50,0.00)$ & $(2.60,0.00)$ \\
\hline & 100 & $(-4.98,0.00)$ & -- & $(-4.27,0.00)$ & $(-4.98,0.00)$ \\
\hline & 67 & $(-0.09,0.58)$ & $(-2.99,0.00)$ & -- & -- \\
\hline & 94 & $(-6.30,0.00)$ & -- & $(-4.81,0.00)$ & -- \\
\hline & 50 & $(-7.29,0.00)$ & -- & $(-3.79,0.00)$ & -- \\
\hline & 4 & $(-4.14,0.00)$ & -- & -- & -- \\
\hline & 27 & $(-3.66,0.00)$ & -- & $(-1.19,0.00)$ & $(7.04,0.00)$ \\
\hline & 28 & $(0.20,0.22)$ & $(3.10,0.00)$ & $(1.97,0.00)$ & -- \\
\hline & 87 & $(3.270,0.000)$ & $(12.220,0.000)$ & $(4.34,0.00)$ & $(3.97,0.00)$ \\
\hline
\end{tabular}

By comparing the results of Taha et al. (2009) and the current study, it is indicated that there is no significance difference between the 5th and 95th percentiles for weight of Saudis in both studies. So, we can conclude that the 5th and 95th percentiles for Saudi weight are 46.65 and $93.69 \mathrm{kgs}$ respectively. Based on the logical decision value in column 6 , there is no statistical evidence that both percentiles values are equal for both studies for the remaining eleven dimensions.

Comparing the data in Tunay and Melemez (2008) and Turgut et al. (2004) for Turkish with the current study indicates that most percentiles are different for the two populations except for hip breadth (sitting) percentiles, 5th percentile of buttock-knee length and 95th percentile for popliteal height (sitting). These percentile values are $31.39,39.17,55.08$ and $46.98 \mathrm{cms}$ respectively. It is worth noting that both Turkish studies give the same result of hypothesis test for sitting hip breadth. So, the 5th and 95th percentile values for hip breadth can be used to design seat width (Mououdi, 1997; Gouvali and Boudolos, 2006; Musa, 2011; Mohamed Thariq et al., 2010; Sanders and McCormick, 1993). 


\begin{tabular}{|c|c|c|c|c|c|c|c|c|c|c|c|c|c|c|c|c|c|c|c|}
\hline \multirow{3}{*}{$\begin{array}{l}\text { US } \\
\text { Ref. } \\
\text { No. }\end{array}$} & \multirow[b]{3}{*}{ Percentiles } & \multirow{3}{*}{$\begin{array}{l}\text { Current } \\
\text { study } \\
\text { percentiles } \\
\text { values }\end{array}$} & \multirow{2}{*}{\multicolumn{2}{|c|}{$\begin{array}{l}\text { Current study } \\
95 \% \text { Confidence } \\
\text { intervals for 5th/ } \\
\text { 95th percentiles }\end{array}$}} & \multirow{2}{*}{\multicolumn{3}{|c|}{$\begin{array}{l}\text { Saudi } \\
\text { Taha et al. (2009) }\end{array}$}} & \multicolumn{6}{|l|}{ Turkey } & \multicolumn{6}{|l|}{ Iran } \\
\hline & & & & & & & & \multicolumn{3}{|c|}{$\begin{array}{l}\text { Tunay and } \\
\text { Melemez (2008) }\end{array}$} & \multicolumn{3}{|c|}{ Turgut et al. (2004) } & \multicolumn{3}{|c|}{ Mirmohammadi et al. (2011) } & \multicolumn{3}{|c|}{ Habibi et al. (2012) } \\
\hline & & & CI-Low & CI-High & Decision & $\mathrm{H}_{1}: \mathrm{b}<\mathrm{H}_{\mathrm{o}}$ & $\mathrm{H}_{1}: \mathrm{b}>\mathrm{H}_{\mathrm{o}}$ & Decision & $\mathrm{H}_{1} \cdot \mathbf{b}<\mathrm{H}_{0}$ & $\mathrm{H}_{1}: \mathrm{b}>\mathrm{H}_{\mathrm{o}}$ & Decision & $\mathrm{H}_{1} \cdot \mathrm{b}<\mathrm{H}_{\mathrm{o}}$ & $\mathrm{H}_{1}: \mathrm{b}>\mathrm{H}_{\mathrm{o}}$ & Decision & $\mathrm{H}_{1} \cdot \mathbf{b}<\mathrm{H}_{0}$ & $\mathrm{H}_{1}: \mathrm{b}>\mathrm{H}_{\mathrm{o}}$ & Decision & $\mathrm{H}_{\mathrm{l}} \cdot \mathrm{b}<\mathrm{H}_{\mathrm{o}}$ & $\mathrm{H}_{1}: \mathrm{b}>\mathrm{H}_{\mathrm{o}}$ \\
\hline \multirow{2}{*}{125} & 5th & 46.65 & 46.62 & 51.69 & 0 & 0.599 & 0.401 & 1 & 1.000 & 0.000 & -- & -- & -- & -- & -- & -- & 1 & 0.999 & 0.001 \\
\hline & 95 th & 93.69 & 90.33 & 94.67 & 0 & 0.964 & 0.036 & 1 & 0.000 & 1.000 & -- & -- & .- & .- & .- & .- & 1 & 0.000 & 1.000 \\
\hline \multirow[t]{2}{*}{100} & 5 th & 161.62 & 160.93 & 162.27 & 1 & 0.000 & 1.000 & 1 & 1.000 & 0.000 & -- & -- & -- & 1 & 1.000 & 0.000 & 1 & 1.000 & 0.000 \\
\hline & 95th & 177.79 & 177.40 & 178.87 & 1 & 1.000 & 0.000 & 1 & 1.000 & 0.000 & -- & -- & -- & 1 & 1.000 & 0.000 & 1 & 1.000 & 0.000 \\
\hline \multirow[t]{2}{*}{13} & 5 th & 41.53 & 41.41 & 42.47 & -- & -- & -- & 1 & 0.000 & 1.000 & 1 & 1.000 & 0.000 & 1 & .000 & 1.000 & 1 & 0.000 & 1.000 \\
\hline & 95th & 53.87 & 53.20 & 54.19 & -- & -- & -- & 1 & 0.000 & 1.000 & 1 & 0.000 & 1.000 & 1 & 0.000 & 1.000 & 1 & 0.000 & 1.000 \\
\hline \multirow[t]{2}{*}{67} & 5 th & 31.39 & 31.11 & 31.70 & 1 & 0.000 & 1.000 & 0 & 0.484 & 0.516 & 0 & 0.484 & 0.516 & -- & -- & -- & -- & -- & -- \\
\hline & 95th & 39.17 & 38.90 & 39.49 & 1 & 1.000 & 0.000 & 0 & 0.291 & 0.709 & 0 & 0.291 & 0.709 & -- & -- & -- & -- & -- & -- \\
\hline \multirow[t]{2}{*}{94} & 5 th & 82.73 & 82.43 & 83.77 & 1 & 1.000 & 0.000 & 1 & 1.000 & 0.000 & -- & - & - & 1 & 0.999 & 0.001 & -- & -- & -- \\
\hline & 95th & 94.11 & 94.11 & 95.98 & 1 & 0.000 & 1.000 & 1 & 1.000 & 0.000 & -- & -- & -- & 1 & 1.000 & 0.000 & -- & -- & -- \\
\hline \multirow[t]{2}{*}{50} & 5 th & 72.12 & 71.40 & 72.18 & 1 & 1.000 & 0.000 & 1 & 1.000 & 0.000 & -- & -- & -- & 0 & 0.069 & 0.931 & -- & -- & -- \\
\hline & 95th & 81.57 & 81.56 & 82.90 & 1 & 0.001 & 0.999 & 1 & 1.000 & 0.000 & -- & -- & -- & 1 & 1.000 & 0.000 & -- & -- & -- \\
\hline \multirow[t]{2}{*}{4} & 5th & 53,98 & 52.81 & 53.98 & 1 & 1.000 & 0.000 & 1 & 1.000 & 0.000 & -- & -- & -- & -- & -- & -- & -- & -- & -- \\
\hline & 95th & 63.38 & 62.40 & 63.38 & 1 & 1.000 & 0.000 & 1 & 1.000 & 0.000 & -- & -- & -- & -- & -- & -- & -- & -- & -- \\
\hline \multirow{2}{*}{122} & 5 th & 19.74 & 19.74 & 20.60 & -- & -- & -- & -- & -- & --000 & - & - & -- & & 1 & 0.000 & 1.000 & - &.-- \\
\hline & 95th & 26.01 & 25.20 & 26.10 & -- & -- & -- & -- & -- & -- & .- & .- & .- & & 1 & 1.000 & 0.000 & .- & -- -- \\
\hline \multirow[t]{2}{*}{27} & 5th & 55.08 & 54.60 & 55.20 & 1 & 0.000 & 1.000 & 0 & 0.050 & 0.950 & -- & -- & -- & 1 & 0.000 & 1.000 & 1 & 1.000 & 0.000 \\
\hline & 95 th & 64.03 & 63.60 & 64.49 & 1 & 0.001 & 0.999 & 1 & 1.000 & 0.000 & -- & - & -- & 1 & 0.001 & 0.999 & 1 & 0.000 & 1.000 \\
\hline \multirow[t]{2}{*}{28} & 5 th & 43.64 & 43.64 & 44.80 & 1 & 0.000 & 1.000 & 1 & 0.000 & 1.000 & 1 & 0.000 & 1.000 & 1 & 0.000 & 1.000 & - & -- & -- \\
\hline & 95th & 52.54 & 52.30 & 53.19 & 1 & 1.000 & 0.000 & 1 & 1.000 & 0.000 & 1 & 0.000 & 1.000 & 1 & 0.000 & 1.000 & -- & -- & -- \\
\hline \multirow[t]{2}{*}{73} & 5 th & 45.38 & 43.71 & 44.20 & 1 & 1.000 & 0.000 & 1 & 1.000 & 0.000 & 1 & 1.000 & 0.000 & 1 & 1.000 & 0.000 & 1 & 1.000 & 0.000 \\
\hline & 95th & 53,04 & 52.40 & 53.20 & 1 & 1.000 & 0.000 & 1 & 1.000 & 0.000 & 1 & 1.000 & 0.000 & 1 & 1.000 & 0.000 & 1 & 1.000 & 0.000 \\
\hline \multirow[t]{2}{*}{87} & 5th & 35.48 & 35.48 & 36.29 & 1 & 1.000 & 0.000 & 1 & 1.000 & 0.000 & 1 & 1.000 & 0.000 & 1 & 1.000 & 0.000 & 1 & 1.000 & 0.000 \\
\hline & 95th & 46.98 & 45.08 & 46.98 & 1 & 1.000 & 0.000 & 0 & 0.451 & 0.549 & 1 & 0.000 & 1.000 & 0 & 0.445 & 0.555 & 1 & 1.000 & 0.000 \\
\hline
\end{tabular}

In general, most of the twelve anthropometric dimensions for Saudi and Iranians are different compared with the results in Mirmohammadi et al. (2011; Habibi et al., 2012) except for the 5th percentile of sitting eye height (72.12) and 95th percentile of the sitting popliteal height (46.98). Based on the $\alpha$ values in columns named $\mathrm{H}_{1}: \mathrm{b}<\mathrm{H}_{\mathrm{o}}$ and $\mathrm{H}_{1}: \mathrm{b}>\mathrm{H}_{\mathrm{o}}$ in Table 8 , it is indicated that the percentile values for Iranians is larger than Saudi so we cannot use the products designed for the Iranians to be used by Saudi people.

\section{Discussion}

In this research, we collected and described 12 anthropometric posture measures for Saudi students at the College of Engineering, King Khalid University, KSA and compared the resulting statistics with the body dimensions of Turkish and Iranian students. We described the posture dimensions of Saudi students based on a sample of 900 students in terms of mean, standard deviation, the 5th and 95th percentiles and significance level for KolmogorovSmirnov normality test. All of the collected data were normally distributed based on the KS test statics significance values that are greater than 0.054. A comparison of the mean anthropometric measures for Saudi students with the Turks and Iranians was done based on the 2 sample $t$ test statistic for normal populations with unknown variances. Also, a comparison of the same populations was made based on the available data in the literature in terms of Ed, confidence intervals and the 2 sample independent $t$ test. Quantile inference based on Hutson (1999) was used to define the 95\% confidence interval for the 5th and 95th percentiles of the collected data and to compare it with published data for Saudi, Turkish and Iranians.

The results of this research show that the anthropometric data for Saudis, Turks and Iranians by different researchers gives different results and that a comparison of their anthropometric dimensions gives different results, this being compatible with the results of the work done by Lin et al. (2004; Farkas et al., 2005; Bélanger et al., 2010). The above results indicate the effect of geographical region on the variation of anthropometric dimensions of humans Sirajuddin et al. (1994; Ali and Arslan, 2009).

It was found that there is a significant difference between the anthropometric data for Saudi students in Taha et al. (2009) and that for the current study, except that the weight and stature in both works are the same, as indicated by the P-values. It is evident that there is no difference between the Turkish dimensions described by Tunay and Melemez (2008; Turgut et al., 2004) that cannot be explained by the fact that the Turkish population consists of only two ethnic groups. Most of the anthropometric data for Iranians depict a significant difference. Moreover, comparing the three populations reveals that there is a greater similarity between the anthropometric data for the Saudis and Turks than between the Saudis and Iranians. However, the similarities between Turkish and Iranian anthropometric data are outweighed by the differences between these populations due to the large number of ethnic groups that constitute the Iranian population. Most of the 5th and 95th percentile values for Saudi are different from the corresponding values for Turkish and Iranians, so we cannot use products designed for them to used by Saudi people.

Calculation showed that the anthropometric data for the peoples of the Middle East differ from each other. Therefore, the anthropometric data collected from the students of KKU can be utilized to better construct furniture for classrooms, laboratories and other education facilities at the College of Engineering at King Khalid University. Also, the results of this study point to the fact 
that Saudi Arabian universities cannot use the existing literature available for the Middle Eastern countries to design furniture for universities.

\section{Conclusion}

The aim of this research was to compare the anthropometric dimensions of Saudi Arabian engineering students at King Khalid University with those of two other Middle Eastern peoples, namely, Turks and Iranians. This study collected data on twelve anthropometric dimensions and described it in terms of the mean, standard deviation, 5th/95th percentile values and significance values of Kolmogroph-Smirnov test for normality based on a sample of 900 students. The stats collected for the Saudi students were compared with the data in the literature covering Turkish and Iranian students. This study implemented the 2 sample $t$ test to compare the means of the two populations with unknown variance as a basis for comparison between the three populations with a level of significance of 0.05 . Hutson (1999) quantile inference was used to compare the 5th and 95th percentiles for the three people at the level of significance of 0.05 .

In conclusion, we found that the body dimensions of Iranian students are significantly different from those of Saudi and Turkish university students. The values of the body weight, bideltoid breadth, buttock-popliteal length and sitting popliteal height of the Saudis were found to be larger than those of the Turkish and Iranian students, while the remaining dimensions were smaller for the Saudis, relative to the Turks and Iranians. Also, based on the collected data, the anthropometric dimensions for one country vary depending on the research. This may be explained by the smaller sample sizes, the neglecting of the ethnic diversity of the conducted research, or limiting the sample to a certain group such as students, farmers, or military persons. The collected data and findings provided additional data on the anthropometric dimensions of Saudi university students. This data will be very useful for providing a benchmark for the design of equipment to be used in the classrooms, libraries, laboratories and theaters/conference halls of universities. This research could be expanded into a comprehensive study to address the collection of anthropometric data for other human dimensions and comparing it with other international populations, especially those of Europe, the USA, Africa and Asia, for which the results could influence the determination of trade volume between these regions.

\section{Acknowledgment}

The author is very grateful to the Industrial Engineering Department, College of Engineering, King Khalid
University, Kingdom of Saudi Arabia for providing all facilities for sampling and measuring processes.

\section{Ethics}

This article is original and contains unpublished material. The author confirms that there are no ethical issues involved.

\section{References}

Aagaard-Hansen, J. and A. Storr-Paulsen, 1995. A comparative study of three different kinds of school furniture. Ergonomics, 38: 1025-1035. DOI: $10.1080 / 00140139508925169$

Agrawal, K.N., R.K.P. Singh and K.K. Satapathy, 2010. Anthropometric considerations of farm tools/machinery design for tribal workers of northeastern India. Agric. Eng. Int.: CIGR J., 12: $143-150$.

Ali, İ. and N. Arslan, 2009. Estimated anthropometric measurements of Turkish adults and effects of age and geographical regions. Int. J. Indust. Ergon., 39: 860-865. DOI: 10.1016/j.ergon.2009.02.007

Bélanger, D., H. Lee and H. Wang, 2010. Ethnic diversity and statistics in East Asia: 'Foreign brides' surveys in Taiwan and South Korea. Ethn. Racial. Stud., 33: 1108-1130. DOI: $10.1080 / 01419870903427507$

Bolstad, G., B. Benum and A. Rokne, 2001. Anthropometry of Norwegian light industry and office workers. Applied Ergon., 32: 239-246. DOI: $10.1016 / \mathrm{S} 0003-6870(00) 00067-3$

Cardon, G., D. De Clercq, I. De Bourdeaudhuij and D. Breithecker, 2004. Sitting habits in elementary schoolchildren: A traditional versus a "Moving school'. Patient Educ. Counsel., 54: 133-142. DOI: $10.1016 / \mathrm{S} 0738-3991(03) 00215-5$

Chung, J.W. and T.K. Wong, 2007. Anthropometric evaluation for primary school furniture design. Ergonomics, 50: 323-334. DOI: $10.1080 / 00140130600842328$

Dianat, I., M. Karimi, A. Asl Hashemi and S. Bahrampour, 2013. Classroom furniture and anthropometric characteristics of Iranian high school students: Proposed dimensions based on anthropometric data. Applied Ergon., 44: 101-108. DOI: $10.1016 /$ j.apergo.2012.05.004

Farkas, L., M. Katic and C. Forrest, 2005. International anthropometric study of facial morphology in various ethnic groups/races. J. Craniofac. Surg., 16: 615-646. DOI: $10.1097 / 01 . s c s .0000171847 .58031 .9 \mathrm{e}$

Fernandez, J., D. Malzahn, O. Eyada and C. Kim, 1989. Anthropometry of Korean female industrial workers. Ergonomics, 32: 491-495. DOI: $10.1080 / 00140138908966119$ 
Gouvali, M. and K. Boudolos, 2006. Match between school furniture dimensions and children's anthropometry. Applied Ergon., 37: 765-773.

DOI: $10.1016 /$ j.apergo.2005.11.009

Habibi, E., N. Sadeghi, F. Mansouri, M. Sadeghi and M. Ranjbar, 2012. Comparison of Iranian student's anthropometric information and American and English standards. J. Jahrom Univ. Med. Sci., 10: 22-30.

Hutson, A., 1999. Calculating nonparametric confidence intervals for quantiles using fractional order statistics. J. Applied Stat., 26: 343-353.

DOI: $10.1080 / 02664769922458$

Jung, H.S., 2005. A prototype of an adjustable table and an adjustable chair for schools. Int. J. Indust. Ergon., 35: 955-969. DOI: 10.1016/j.ergon.2005.04.007

Karmegam, K., S. Sapuan, M. Ismail, N. Ismail and M. Bahri et al., 2011. Anthropometry of Malaysian Young Adults. J. Human Ergol., 40: 37-46. PMID: 25665206

Khalaf, A., Ö. Ekblom, J. Kowalski, V. Berggren and A. Westergren et al., 2013. Female university students' physical activity levels and associated factors-a cross-sectional study in southwestern Saudi Arabia. Int. J. Environ. Res. Public Health, 10: 3502-3517. DOI: $10.3390 /$ ijerph10083502

Koskelo, R., K. Vuorikari and O. Hänninen, 2007. Sitting and standing postures are corrected by adjustable furniture with lowered muscle tension in high-school students. Ergonomics, 50: 1643-1656. PMID: 17917904

Lin, Y., M. Wang and E. Wang, 2004. The comparisons of anthropometric characteristics among four peoples in East Asia. Applied Ergon., 35: 173-178. DOI: $10.1016 /$ j.apergo.2004.01.004

Martin, L. and B. Soldo, 1997. Racial and Ethnic Differences in the Health of Older Americans. 1st Edn., National Academy Press, Washington, D.C., pp: 300 .

Mebarki, B. and B. Davies, 1990. Anthropometry of Algerian women. Ergonomics, 33: 1537-1547. DOI: $10.1080 / 00140139008925352$

Milanese, S. and K. Grimmer, 2004. School furniture and the user population: an anthropometric perspective. Ergonomics, 47: 416-426. DOI: $10.1080 / 0014013032000157841$

Mirmohammadi, S., A. Mehrparvar, S. Jafari and M. Mostaghaci, 2011. An assessment of the anthropometric data of Iranian University students. Int. J. Occup. Hygiene, 3: 85-89.

Mohamed Thariq, M., H. Munasinghe and J. Abeysekara, 2010. Designing chairs with mounted desktop for university students: Ergonomics and comfort. Int. J. Indust. Ergon., 40: 8-18.

DOI: $10.1016 /$ j.ergon.2009.10.003
Mortazavi, S.B., J. Kanani, A. Khavanin, R. Mirzaei and Y. Rasoolzadeh et al., 2008. Foot anthropometry by digital photography and the importance of its application in boot design. J. Mil. Med., 10: 69-80.

Motamedzade, M., M.R. Hassan Beigi and H. Mahjoob, 2009. Design and development of an ergonomic chair for Iranian office workers. ZUMS J., 17: 45-52.

Mououdi, M., 1997. Static anthropometric characteristics of Tehran University students age 20-30. Applied Ergon., 28: 149-150. DOI: 10.1016/S0003-6870(95)00060-7

Murphy, S., P. Buckle and D. Stubbs, 2004. Classroom posture and self-reported back and neck pain in schoolchildren. Applied Ergon., 35: 113-120.

DOI: 10.1016/j.apergo.2004.01.001

Musa, A., 2011. Anthropometric evaluations and assessment of school furniture design in Nigeria: A case study of secondary schools in rural area of Odeda, Nigeria. IJIEC, 2: 499-508. DOI: $10.5267 /$ j.ijiec.2011.03.006

Musaiger, A.O. and H.M. Al-Hazzaa, 2012. Prevalence and risk factors associated with nutrition-related noncommunicable diseases in the Eastern Mediterranean region. Int. J. General Med., 5: 199-217. DOI: 10.2147/IJGM.S29663

Openshaw, S. and E. Taylor, 2006. Ergonomics and Design: A Reference Guide. 1st Edn., Allsteel Inc., USA.

Pentikis, J., M. Lopez and R. Thomas, 2002. Ergonomics evaluation of a government office building. Work, 18: 123-131. PMID: 12441576

Pheasant, S. and C.M. Haslegrave, 2005. Bodyspace: Anthropometry, Ergonomics and the Design of Work. 1st Edn., CRC Press, ISBN-10: 0415285208, pp: 352.

Prado-Lu, J.L.D., 2004. Risk factors to musculoskeletal disorders and anthropometric measurements of Filipino manufacturing workers. Int. J. Occup. Saf. Ergon., 10: 349-359.

DOI: $10.1080 / 10803548.2004 .11076618$

Sadeghi, F., A. Bahram and A. Jafari, 2014. Comparison of static anthropometric characteristics among workers of three Iranian ethnic groups. Anthropologist, 18: 601-608.

Sadeghi, M., L. Tajik, S. Karimi, M. Fereidan and A. Hassanzadeh, 2010. Study of educational furniture conformity with students anthropometric dimensions of Isfahan university of medical sciences. Yafteh, Quart. Res. J. Lorestan Univ. Med. Sci., 11: 75-80.

Sanders, M.S. and E.J. McCormick, 1993. Applied Anthropometry, Work-Space Design and Seating. In: Human Factors in Engineering and Design, Sanders, M.S. and E.J. McCormick (Eds.), McGraw-Hill, Singapore, ISBN-10: 007054901X, pp: 415-455. 
Shaheen, A., B. El-Sobkey and H.M. Ibrahim, 2011. Anthropometric measurement and ventilatory function in obese and non-obese female college students. Middle East J. Sci. Res., 7: 634-642.

Sirajuddin, S.M., R. Duggirala and M.H. Crawford, 1994. Population structure of the chenchu and other South Indian tribal groups: Relationships between genetic, anthropometric, dermatoglyphic, geographic and linguistic distances. Human Biol., 66: 865-884.

Taha, Z., I.M. Jomoa and H.R. Zadry, 2009. A study of anthropometric characteristics between Malaysian and Saudi Arabian males aged 20 to 30 years. J. Hum. Ergol., 38: 27-32. PMID: 20034316

Tunay, M. and K. Melemez, 2008. An analysis of biomechanical and anthropometric parameters on classroom furniture design. Afr. J. Biotechnol., 7: 1081-1086.
Turgut, M.M., S.K. Sümer and A. Sabanc1, 2004. Cukurova University classrooms, a student research on compliance with the anthropometric dimensions. Proceedings of the 24th National Congress of Industrial Engineering and Operations Research (EOR' 04), Gaziantep, Adana.

Wang, M.J., E.M.Y. Wang and Y.C. Lin, 2002. The anthropometric database for children and young adults in Taiwan. Applied Ergon., 33: 583-585. DOI: $10.1016 / \mathrm{S} 0003-6870(02) 00032-7$

Wichansky, A., 2000. Usability testing in 2000 and beyond. Ergonomics, 43: 998-1006.

DOI: $10.1080 / 001401300409170$ 